\title{
Participatory scenario planning and framing of social-ecological systems: an analysis of policy formulation processes in Rwanda and Tanzania
}

\author{
Lucas Rutting $^{1}$, Joost M. Vervoort ${ }^{1,2,3}$, Heleen Mees $^{1}$ and Peter P. J. Driessen $^{1}$
}

\begin{abstract}
Governance of social-ecological systems (SES) involves multiple stakeholders with different perspectives on the system and associated problems, and different ways to value and use the system. This has implications for decision making because this diversity of interests and framings may cause conflicts between stakeholders and/or marginalization of certain groups. In general, the literature agrees that strategically considered stakeholder participation is key to well-informed and legitimate SES governance and to alleviate differences and conflicts between stakeholders. Because SES represent uncertain, complex governance contexts, methodologies that address complexity and future uncertainty are needed. In this regard, participatory scenario planning is widely regarded as a useful tool. However, little explicit analysis exists about its role in framing. We therefore analyzed two scenario-guided policy formulation cases to assess how and to what extent it contributes to system and problem framing. We developed an analytical framework building on critical systems and resilience scholarship: the questions of "resilience of what, to what, for whom and over what timeframe?" are important framing dimensions. As such, we used them as the basis for our framework. We analyzed two scenario-guided policy formulation processes in East Africa, facilitated by the CGIAR's Research Program on Climate Change, Agriculture and Food Security. We found that participatory scenario planning significantly contributes to system and problem framing and can add to efficacy, legitimacy, and analytical rigor of planning processes through involving a diverse range of stakeholders in strategic dialogues about futures. Our results also highlight its potential to make the political dimension of policy and broader SES governance processes more explicitly visible by addressing the "for whom?" dimension. We recommend designing novel participatory scenario approaches that explicitly use insights from critical system theory, incorporating questions of who decides how the system and problems are framed, who should benefit, and whose knowledge is used.
\end{abstract}

Key Words: governance; policy formulation; problem framing; scenarios; social-ecological systems; system framing

\section{INTRODUCTION}

Berkes and Folke (1998) developed the concept of socialecological systems (SES) as an analytical framework for the study of the linkages between ecosystems on the one hand and human systems and institutions on the other. In this framing, the governance of these SES typically involves multiple groups of actors (Folke 2006, Lebel et al. 2006, Ostrom 2009, Berkes 2017), who can be considered part of the SES themselves (Ostrom 2009). Natural resources within such an SES are used by different actors (Ostrom 2009, 2011), to different ends (MEA 2005, Ostrom 2009), in interconnected ways (Berkes 2003, Folke 2007), and across levels (Gibbons 1999, Cash et al. 2006, Cumming et al. 2006, Folke 2007, Vervoort et al. 2012a, Tendall et al. 2015). Unavoidably, these actor groups often differ in terms of their perspectives on, understandings of, and uses of an SES (Dewulf et al. 2004, Ash et al. 2010, Brugnach and Ingram 2012, Herrera 2017, Helfgott 2018). This may lead to differences in what and who they consider part of the system. As a consequence, certain groups of actors may perceive something as a problem, whereas others do not. In other words, different groups of actors oftentimes frame the SES in different ways and define the system's boundaries differently (Midgley 1992, Ulrich 1996, Midgley et al. 1998, Helfgott 2018); as a consequence, they also define system properties such as the system's resilience differently: resilience "of what, to what, for whom, and over what timeframe" may be defined differently by different actors (Carpenter et al. 2001, Helfgott 2018). Moreover, they tend to frame the problems arising in the SES differently as well (Brugnach et al. 2008, Dewulf and Bouwen 2012, Giordano et al. 2017). This has implications for decision making because this diversity of interests and framings may lead to conflicts between actor groups (Shepherd and Bowler 1997, Dewulf et al. 2009). Another potential consequence of these differences is marginalization of certain actor groups because powerful actors can define the boundaries of the system under consideration in such a way that other actors are not considered part of the system (Midgley et al. 1998).

We argue that participatory scenario planning is a useful foresight tool for decision making in complex SES and can therefore help accommodate such differences in system and problem framings and resulting conflicts, and thereby enhance governance processes in SES. Different scholars state that participatory scenario planning can contribute to more sound decision making through deliberative consultation of diverse stakeholders, as well as through facilitating the framing and re-framing of an SES, the problems it faces, and potential solutions (Patel et al. 2007, Garb et al. 2008, Pulver and VanDeveer 2009). Stakeholder participation, in a more general sense, is often presented as a way to accommodate differences between actor perspectives and framings (Whyte 1991, Dryzek 2000, Dewulf et al. 2005, Mostert et al. 2007), as well as improve legitimacy (Stirling 1999) and make the decision-making process more democratic (Glucker et al. 2013), i.e. respecting and bringing together the different values and understandings in society. Furthermore, some scholars claim that stakeholder participation can improve efficacy of decision

${ }^{1}$ Copernicus Institute of Sustainable Development, Utrecht University, ${ }^{2}$ Environmental Change Institute, University of Oxford, ${ }^{3}$ Research Institute for Humanity and Nature, Kyoto 
making (Stirling 1999) and that it can be instrumental in helping to resolve conflicts through public deliberation (Shepherd and Bowler 1997, Glucker et al. 2013) and social learning (Mostert et al. 2007). In addition, as Stirling (1999) argued, it can play a significant role in contributing to the analytical rigor of decision making. Put differently, stakeholder participation can help to include as much relevant information as possible to make the bestinformed decision possible (O'Faircheallaigh 2010), or to contribute to the substantive quality of the decision-making process (Mostert et al. 2007, Glucker et al. 2013).

Thus, in general, the literature agrees that stakeholder participation is key to efficacious, legitimate, and well-informed SES governance. However, we argue that in light of long-term future uncertainty, participation in itself is not sufficient. Governance of SES involves decision making that typically ought to have an effect on, and be affected by, uncertain futures. Hence, there is a need for methodologies that interrogate and challenge stakeholders' ideas and assumptions about the present and the future (Wilkinson and Eidinow 2008), in other words, methodologies that foster a framing of the system and its problems under consideration that is cognizant of long-term uncertainty.

Participatory scenario planning is widely regarded as a useful tool for decision making in uncertain contexts, such as SES (Peterson et al. 2003, Wilkinson and Eidinow 2008, Oteros-Rozas et al. 2015, Wiebe et al. 2018). It offers an appropriate and effective way to assess proposed policies and strategies for governing SES in terms of their feasibility and robustness in the longer term, through "stress-testing" them against challenging futures or scenarios (Fahey and Randall 1998, Schoemaker et al. 2013, Wiebe et al. 2018). Scenarios, in this regard, can be (ideally) defined as diverse and internally consistent descriptions of plausible futures that might unfold, describing contextual conditions with relevance to a certain decision-making question and to specific actors, connecting both scientific information and different actor perspectives (Wack 1985a, b, Schwartz 1991, van der Heijden 1996, van Notten et al. 2003, Bohensky et al. 2006, Kok et al. 2006, Ramírez and Selin 2014).

Moreover, participatory scenario planning can potentially help to understand, or at least acknowledge, the complexities that continuously arise in SES and governance thereof (Lord et al. 2016). Furthermore, it has the potential to facilitate discussion and to expose conflicts between actors (Oteros-Rozas et al. 2015). In addition, psychological research reveals that people focusing on certain issues typically tend to miss key signals from the area outside the focus, the periphery (Schoemaker 1993, Schoemaker et al. 2013). People naturally tend to reason about the future based on experiences in the present and the recent past. This is, however, often highly misleading when planning for the future, especially when discontinuities such as new technologies occur. Scenarios have the potential to make people more aware of developments and trends outside of their immediate focus and in the periphery, and to make them more sensitive to weak signals, i.e., "seemingly random or disconnected pieces of information that at first appear to be background noise but which can be recognized as part of a larger pattern when viewed through a different frame or by connecting it with other pieces of information" (Schoemaker et al. 2013:815). In this way, scenarios can stimulate people to critically examine and re-think their assumptions about the past, present, and future (Wack 1985a, b, Schwartz 1991, Schoemaker 1993, van der Heijden 1996, van Notten et al. 2003, Ramírez and Selin 2014).

Participatory scenario planning has the potential to contribute to better information input by incorporating a wide range of viewpoints from different stakeholders into the process. Moreover, it can help stakeholders to filter, integrate, interpret, and make sense of the multitude of signals in the periphery (Schoemaker et al. 2013). And it also has the potential to help rethink and reframe "taboos" in policy contexts, thereby introducing them into the discussion (Schoemaker and Tetlock 2012). Therefore, it is thought that participatory scenario planning can help to frame the system and problems it faces in a more comprehensive manner, by broadening the scope of what to consider, thereby fostering a better system understanding.

We define system framing as determining system boundaries, to what and who are considered part of the system under consideration. These boundaries are defined in terms of both biophysical and social aspects, including which actors are considered decision makers and stakeholders (Churchman 1970, Ulrich 1994). In this regard, critical systems theory is relevant because it provides a critical perspective on and approach to complex systems theory. It poses such questions as which boundaries are or might be used when analyzing a system and their implications for intervention (Midgley et al. 1998), and what to include or exclude in processes of decision making, as well as how the system under consideration is defined. What is considered an improvement in the system depends on how system boundaries are defined. In general, crucial trade-offs exist between practical action and what to include within the boundaries of the system (Midgley et al. 1998).

Moreover, we define problem framing as understandings and representations of problems or issues, which may differ depending on actors' perspectives. These differences in issue framing play a role in conversations for change (such as participatory scenario planning processes for SES governance). Dewulf and Bouwen (2012) introduced the interactional approach to issue framing; people seek to comprehend complex situations and make sense of ambiguous issues in an interactional way, for themselves and also for others. Through deliberation and negotiation, situations are characterized as problems, the causes of these problems are discussed, and the responsible actors identified (Dewulf et al. 2009).

All in all, there is a general sense when surveying the literature that scenarios add to appropriate system and problem framing. Existing work on participatory scenario planning describes how it may contribute to processes related to framing in more general terms. In addition, different scholars have published on the role of framing processes in participatory policy processes (e.g., Smith and Stirling 2010, Adger et al. 2011, Brugnach et al. 2011, Dewulf and Bouwen 2012). However, we still lack understanding on how exactly participatory scenario planning contributes to system and problem framing in practice. No concrete analyses of empirical cases on the actual contribution of participatory scenario planning to system and problem framing have been conducted 
yet. Therefore, our objective is to analyze how and to what extent participatory scenario planning contributes to system and problem framing in policy formulation processes for governance of SES. To this end, we aim to unpack the link between participatory scenario planning and framing, and to provide empirical evidence for this. We focus on changes in framing that may lead to improved policies for SES governance, for instance through broadening the definition of the system, consideration of perspectives of all stakeholders, or by considering multiple problem perceptions. To address our main objective, we analyze two cases in which participatory scenario planning was employed to guide policy formulation processes, which we regard an important component of SES governance. More specifically, participatory scenario planning was used to guide policy formulation. We regard the policy formulation phase as a key phase of SES governance because this is the phase devoted to generating options for addressing public problems (Turnpenny et al. 2015). These cases took place in Tanzania and Rwanda, both located in the Lake Victoria basin area in East Africa. Both cases were initiated by the CGIAR's Research Program on Climate Change, Agriculture and Food Security (CCAFS) in collaboration with national governments and focused on policies on agriculture, other forms of land use, and the environment. Climate Change, Agriculture and Food Security has a decadelong experience in science-policy engagement processes in the Global South, based on existing networks and relationships (Dinesh et al. 2018). The CCAFS Scenarios Project has been an integral part of the program, with successful participatory scenario processes employed across six global regions (Chaudhury et al. 2013, Vermeulen et al. 2013, Vervoort et al. 2014, Palazzo et al. 2017, Wiebe et al. 2018). Typically, these scenario processes are building on existing policy development processes, which allows for more effectiveness and greater leverage (Vermeulen and Campbell 2015, Dinesh et al. 2018).

\section{ANALYTICAL FRAMEWORK}

We aim to analyze the role of participatory scenario planning (our independent variable) in system and problem framing (our dependent variable) in policy formulation processes, which ultimately influences the governance of SES. For this analysis, we build on work on the resilience of SES and on critical systems theory, which provides a comprehensive and useful perspective on system framing and problem framing (Carpenter et al. 2001, Helfgott 2018). Carpenter et al. (2001) argued that to understand resilience, it is important to ask two questions: resilience of what, and to what? Building on this, a number of scholars formulated a couple of additional questions arguing that it is important to also ask on what timeframe resilience is defined, and for whom (Lebel et al. 2006, Cretney 2014, Herrera 2017, Helfgott 2018, Meerow and Newell 2019). We use these four questions as dimensions to operationalize system and problem framing, as shown in Table 1. It is important to note that we do not attempt to address system resilience, but rather use the frameworks developed by the aforementioned scholars as a basis for our analytical framework.

We regard the questions "of what?," "to what?," "for whom?," and "over what timeframe?" as important framing dimensions in the participatory scenario planning process. Using these dimensions, we can analyze how actors define the system of focus and how this may change in the future (of what?), which current and future disturbances it faces and should therefore be addressed in the policy (to what?), who are defined as the actors involved in the process and are supposed to benefit from it (for whom?) and, importantly, the dimension of time (over what timeframe?), which can be regarded as a cross-cutting dimension, i.e., each of the other three dimensions may change with time. We consider these four questions as operationalizations of system and problem framing. It is important to note that system and problem framing prove to be hard to separate in practice because both are subject to interpretation by different actors due to different boundary judgements. Therefore, we consider all four dimensions to be relevant for both system and problem framing. As such, these four dimensions represent the dependent variable of interest.

Per dimension, we formulated a set of guiding questions, based on different literatures. For the dimension 'of what,' we identified Ostrom's SES framework (2009) as particularly useful. Ostrom defined an SES as consisting of four subsystems: the resource system, resource units, the governance system, and the users or actors. These different subsystems interact with each other. Examples of resource systems are forests, agricultural systems, lakes and marine systems, and protected terrestrial parks. Resource units can be trees, wildlife, crops, fish, etc. In Ostrom's framework, governance systems typically consist of a government and other managing organizations. And finally, users are all actors that use the resource system in diverse ways for commercial purposes, food production, cultural purposes, recreation, and so forth. This led to a set of guiding questions displayed in Table 1 (questions 1-3).

For the dimension 'to what,' Biggs et al. (2012) stated that SES face both unexpected shocks and disturbances (on a short timescale) and slower on-going change on the longer term. This has led us to formulate questions regarding disturbances on different timescales (Table 1, questions 4-5). Furthermore, because scenarios allow for an exploration and investigation of contextual conditions for specific policies, they can bring in drivers operating at different levels, from the local to the global level (Wiebe et al. 2018; Table 1, question 6). In addition, we argue, scenarios can articulate both changing external drivers and internal processes in an SES, both of which are key when looking at SES dynamics (Adger 2000, Folke et al. 2010; Table 1, question 7). Also, because the future is shaped by an interplay of drivers such as climate, technological, socioeconomic, and political change, it is key to consider these different drivers (Maier et al. 2016; Table 1, question 8).

For the 'for whom' dimension, we build on Stirling's (1999) participation framework. First, it is important to ask the question which stakeholders are involved in the policy process (Table 1, question 9). Second, the questions "who is supposed to benefit from the policy," and "who is affected," are key in our analysis (legitimacy in Stirling's framework; Table 1, questions 10-11). Third, we focus on who is contributing to the policy process in terms of knowledge and experience (analytical rigor in Stirling's framework; Table 1, question 12). It is important to remark that typically the goal in participatory scenario processes is to involve all stakeholders that are affected and/or supposed to benefit from the process. 
Table 1. Analytical framework.

\begin{tabular}{|c|c|}
\hline Dimension & Guiding questions \\
\hline Of what? & $\begin{array}{l}\text { 1. What comprises the resource system, the ecosystems? } \\
\text { 2. What comprises the governance system? } \\
\text { 3. What are considered resource units? } \\
\text {--Based on Ostrom } 2009\end{array}$ \\
\hline To what? & $\begin{array}{l}\text { 4. Which shocks and disturbances to the system on a short time scale are considered? } \\
\text { 5. Which longer-term changes and developments impacting the system are considered? } \\
\text { 6. Are drivers on different levels (local, national, regional, global) considered? } \\
\text { 7. Which external drivers and internal processes are considered (exogenous and endogenous drivers)? } \\
\text { 8. What different drivers, such as climate, technological, socioeconomic, and political change are considered? } \\
\text {--Based on Adger 2000, Folke et al. 2010, Biggs et al. 2012, Walker et al. 2012, Maier et al. 2016, and Wiebe et al. } 2018\end{array}$ \\
\hline For whom? & $\begin{array}{l}\text { 9. Who are governing/making decisions? Who are involved in the policy process (efficacy)? } \\
\text { 10. Who are supposed to benefit from the policy? } \\
\text { 11. Who are affected/influenced by the policy (legitimacy)? } \\
\text { 12. Who contribute to the process in terms of knowledge and experience (analytical rigour)? } \\
\text {--Based on Stirling (1999) }\end{array}$ \\
\hline Over what timeframe? & $\begin{array}{l}\text { 13. What is the time horizon of the policy? } \\
\text { 14. Are different time scales considered (processes taking place on different time scales)? } \\
\text { 15. Are fast and slow variables considered? } \\
\text {--Based on Biggs et al. 2012, Vervoort et al. 2012, Walker et al. 2012, and Helfgott } 2018\end{array}$ \\
\hline
\end{tabular}

Last, for the time dimension, we follow Helfgott (2018) in looking at the time horizon of the policy (Table 1, question 13). This is important because the timeframe determines which drivers and disturbances are considered in the policy and which actions are proposed to tackle problems caused by these drivers. Key guiding questions for this dimension focus on the timeframe itself (Helfgott 2018), different time scales (Biggs et al. 2012, Vervoort et al. 2012a; Table 1, question 14) and on the consideration of both 'fast' and 'slow' variables in SES; here, fast variables are often variables of prime concern to users, such as crop production, and slow variables refer to generally slower, underlying variables, such as the amount of soil organic matter, which determines crop production to a large degree (Walker et al. 2012; Table 1, question $15)$.

Answering these descriptive questions for both the situations before and after the participatory scenario planning process, we can analyze the difference, and thus determine its contribution to system and problem framing.

\section{METHODS}

To address our research objective, we analyzed two cases in East Africa in which the participatory scenario planning process of CGIAR's Climate Change, Agriculture and Food Security program was applied. This is a type of science-policy engagement process that is part of a long-running program building on existing networks (Chaudhury et al. 2013, Vervoort et al. 2014, Palazzo et al. 2017, Dinesh et al. 2018). Similar scenario-supported policy guidance processes are conducted in the CCAFS program, always focusing on the use of scenarios to evaluate and improve specific policies and strategies. We chose to focus on two cases of scenarioguided policy formulation facilitated by the Scenarios Project of CCAFS, in Rwanda and Tanzania. Both cases were similar in terms of project context, geographical context, and both processes followed the scenarios methodology developed within CCAFS (Vervoort et al. 2014). The two processes differed in terms of the specific policy theme and country-specific governance conditions. In our analysis, we do not focus on these country- specific conditions because differences between the two case study countries make assessing and comparing the impact of the participatory scenario process on the final policy and implementation thereof difficult, if not impossible. In Rwanda, the Livestock Master Plan (LMP) was reviewed (Kiker et al. 2020). The scenario-guided review process was organized by the CCAFS Scenarios Project, the Livestock Systems Innovation Lab (LSIL) at the university of Florida, and the International Livestock Research Institute (ILRI). The LMP was developed by researchers at ILRI with input from experts and policymakers at the Rwandan Ministry of Agriculture and Animal Resources (MINAGRI) and Rwanda Agriculture Board (RAB) of The Republic of Rwanda, as well as other Rwandan livestock experts, under auspices of the Rwandan Minister of Agriculture. Its overall objective is to "meet the Rwandan national development objective of improving food and nutrition security" (ILRI and MINAGRI 2017:3). The development of the LMP was funded by the United Nations Food and Agriculture Organization (FAO). In Tanzania, the National Environmental Policy (United Republic of Tanzania 2014) was reviewed (Muchunguzi et al. 2015). The review process was organized by the CCAFS Scenarios Project and the International Institute of Tropical Agriculture (IITA), in close collaboration with Tanzania's Vice President's Office. The National Environmental Policy was the product of close consultation and partnership between the Vice President's Office (the governmental body responsible for the policy) and other stakeholders, including private sector actors, civil society, and environmental NGOs. The 2014 policy was the product of an extensive review of the first version developed in 1997 , considering concurrent trends and emerging environmental challenges. The policy's overall vision is to contribute to "the sustainable management of the environment and rational exploitation of natural resources providing desired ecosystem services and a balanced and equitable development" (United Republic of Tanzania 2014:7). Workshop participants included representatives of the ministry responsible for the policy, researchers, and other stakeholders. In the Rwanda case, the LSIL team of the University of Florida and ILRI (with connections in 
Table 2. Case study characteristics.

\begin{tabular}{|c|c|c|}
\hline Case & Rwanda & Tanzania \\
\hline Description & $\begin{array}{l}\text { Scenario-guided review of the Livestock Master Plan (LMP), } \\
\text { organized by Climate Change, Agriculture and Food Security } \\
\text { (CCAFS) and the University of Florida. The LMP was } \\
\text { prepared by the International Livestock Research Institute } \\
\text { (ILRI), with input from the Ministry of Agriculture and } \\
\text { Animal Resources and Rwanda Agriculture Board of The } \\
\text { Republic of Rwanda, and other Rwandan livestock experts. The } \\
\text { study was funded by the United Nations Food and Agriculture } \\
\text { Organization (FAO). Carried out in September } 2019 \text {. }\end{array}$ & $\begin{array}{l}\text { Scenario-guided review of the first draft revision of the } \\
1997 \text { National Environmental Policy formulated in } 2014 \text {. } \\
\text { Organized by CCAFS in collaboration with the Tanzanian } \\
\text { Vice-President's Office, the governmental body responsible } \\
\text { for the policy. Carried out in February } 2015 \text {. }\end{array}$ \\
\hline Participants & $\begin{array}{l}\text { Government representatives, researchers; private sector actors } \\
\text { (industry associations); NGO (Vétérinaires Sans Frontières). }\end{array}$ & $\begin{array}{l}\text { Government representatives from the Vice-President's } \\
\text { Office and various other ministries (focusing on } \\
\text { agriculture and food security, livestock and fisheries, } \\
\text { natural resources and tourism, water, health, transport, } \\
\text { education); researchers. }\end{array}$ \\
\hline Documents analyzed & $\begin{array}{l}\text { Rwanda Livestock Master Plan (ILRI and MINAGRI 2017); } \\
\text { Workshop Report: Scenario-guided review of the Rwanda } \\
\text { Livestock Master Plan (Kiker et al. 2020). }\end{array}$ & $\begin{array}{l}\text { First Draft Revised National Environmental Policy } \\
\text { (United Republic of Tanzania 2014); Scenario-guided } \\
\text { policy development in Tanzania in the context of climate } \\
\text { change: a review of the National Environmental Policy } \\
\text { (Muchunguzi et al. 2015). }\end{array}$ \\
\hline
\end{tabular}

Rwanda), in consultation with the Rwandan Ministry of Agriculture, selected and invited participants for the scenarioguided review process. In the Tanzania case, the participants were selected and invited by researchers at IITA, who have connections in the East-African region, including in Tanzania, in consultation with the Vice President's Office. Table 2 gives an overview of the main characteristics of the two cases.

In both cases, a two-day workshop was organized in collaboration with the governmental body responsible for the policy under consideration. The workshops followed a similar procedure. They both started with an initial review of the old or current version of the policy under review. The policy under review was subdivided into four (in the Rwanda case) or five (in the Tanzania case) parts, which were then critically examined by breakout groups consisting of a mix of participants; each so-called 'policy breakout group' consisted of participants representing different actor groups. Participants asked themselves what was missing in the policy document (e.g., subsectors, threats to the system, etc.) and what could be improved, and documented this. This way, participants' system and problem framings before the scenario process were captured before the scenario process was initiated: a useful step to help distinguish the difference between the general bringing together of stakeholders and the impacts of the scenario analysis.

After the initial analysis of the policy document, four new groups were formed. Each of these new groups consisted of participants from all policy breakout groups and a healthy mix of different stakeholders groups. The groups developed a country-specific future scenario, each describing a different plausible future. In both the Rwandan and the Tanzanian case, these adapted scenarios were based on a previously developed set of four scenarios describing futures for the region of East Africa, developed during a range of sessions attended by stakeholders from Ethiopia, Kenya, Tanzania, Burundi, Rwanda, and Uganda, from different backgrounds but with a shared interest in food security, environments, and livelihoods (Vervoort et al. 2013). This scenario set was based on two structuring drivers, describing the degree of political and economic regional integration in East Africa, and whether the mode of governance will be primarily characterized by a reactive or proactive stance among governments, the private sector, and civil society when it came to agriculture, food security, and climate change (Chaudhury et al. 2013, Vervoort et al. 2013, 2014). The CCAS East Africa scenario set is described in more detail in Appendix 1. The country-specific scenarios were developed in three steps. First, after one of the four different East Africa scenarios was assigned to the different groups, each group immersed themselves in their specific scenario, and group participants individually wrote down thoughts as to what the scenario would mean for their specific country and the scope of the policy for the coming decades. During this step, they primarily focused on broader, contextual developments, such as political and institutional developments, socioeconomic and demographic developments, developments in culture, norms, and values, technological and scientific developments, and developments related to natural resources and ecology. Then, they discussed their ideas with the other group members, building a coherent scenario for their country. Thereafter, they added more detail to the scenario narrative, incorporating elements with specific relevance to the policy under review.

After this, these national-level scenarios were used to review the policy, to assess its feasibility and robustness under diverse and challenging future contexts, and to identify blind spots in the policy. This was done by having each group of participants who had adapted one of the four scenarios, analyze the plan or policy from that scenario perspective. Subsequently, participants formulated recommendations to improve the policy based on the scenario-guided review. Participants' system and problem framings after the scenario process were captured in scenario descriptions, in which additional system elements and drivers they identified were articulated.

To shed light on the question central to this research, we conducted a qualitative content analysis of the system and problem framings in the initial policy documents and the workshop results, both the "raw' results, i.e., workshop notes, and 
the workshop reports. This way, we analyzed these framings before, in the initial policy, and after the participatory scenario planning process, in the scenarios themselves. Table 2 gives an overview of the documents we analyzed. We used the questions in our analytical framework to structure the analysis; these questions served as codes for a deductive content analysis.

Results of the analysis of the two cases are presented. We would like to point out that the first author was involved in both cases as a workshop facilitator. The facilitation of the participatory scenario planning process was aimed at helping participants frame the system and problems under consideration and helping them conceptualize and frame different future scenarios. In doing so, the researcher encouraged participants to actively think about how they perceive the system of focus and related problems. It should, however, be noted that the researcher did not interfere with the content of participants' framings and conceptualizations.

\section{RESULTS}

Overall, we observe that, in both cases, participatory scenario planning had a significant effect on the framing of the systems in question, as well as on associated problems. However, the extent to which it contributed to system and problem framing highly depends on the initial framing in the policy. An overview of the results of our analysis is provided in Table 3 .

\section{Dimension 1: of what?}

In both cases, we observed that participatory scenario planning contributed to a substantial broadening of the framing "of what" comprises the system in the case of a narrowly defined sector plan. In the Rwandan case, the original Livestock Master Plan (LMP) has a narrow focus on the livestock system in Rwanda and frames it primarily in economic terms, for example:

\begin{abstract}
If the proposed investments - of about USD 287 million over the 5-year LMP period - 47\% from the public sector and $53 \%$ from private sector investors - were successfully implemented, the resulting further modernization of the sector has the potential to have a substantial positively impact on livestock keepers by increasing their incomes and the food and nutritional security of their households (ILRI and MINAGRI 2017:1).
\end{abstract}

The participatory scenario planning process helped to open up the scope to a large extent. It helped to reframe the livestock sector as embedded within a wider economic system, including the role of international trade, the role of values, and agency and active role of non-governmental actors in the livestock sector, especially entrepreneurs, as illustrated by this passage from the scenarios in the workshop report:

The economies became diversified with lots of specialized niches for all sorts of businesses [...] The entrepreneur is king and also created lots of jobs (Kiker et al. 2020:11).

This raised questions regarding the sector as malleable by the government and the role of the government in general, as some scenarios showed the possibility of a much more limited role of the government, for example:

The governments then took a backstep and trusted selfregulatory mechanisms within industries (Kiker et al. 2020:11).
In the case of the Tanzanian New Environmental Policy (NEP), the participatory scenario planning process contributed to reframing of the system the policy focused on to a much lesser extent. This can be attributed to the broader initial framing of the NEP, which covers a wide range of topics, including different land-use sectors, such as agriculture, fisheries, and mining; human settlements; road and sanitation infrastructure; energy, tourism, and the impacts on ecosystems; and the environment in general (United Republic of Tanzania 2014). It prompted, however, a consideration of power dynamics between actors involved in the SES, with certain scenarios highlighting power dynamics between actors, and consideration of coordination across different landuse sectors, as exemplified in this quote from one of the Tanzania scenarios:

Food security has increased over the years as a result of economic growth, strategic planning, and multisectoral collaboration, between government and private sector actors across sectors and civil society (Muchunguzi et al. 2015:40).

Furthermore, it pointed to the possibility of an inactive government, i.e., "ineffective governance systems with inaction of the government and lack of effective decentralizations" (Muchunguzi et al. 2015:28), poor policy implementation, i.e., "environmental policy implementation has no ownership" (Muchunguzi et al. 2015:32), and a lack of governmental capacity at all levels, i.e., "the government lacks, at all levels, continuity in planning and implementation” (Muchunguzi et al. 2015:28).

\section{Dimension 2: to what?}

A similar pattern was observed when it came to the contribution of participatory scenario planning to the framing of the question 'to what?'; broadly speaking the endogenous and exogenous drivers impacting the focus system. In the case of the Rwandan LMP, the initial focus was on sector-specific issues and challenges, such as feed availability, animal health, animal breeds, and marketing of livestock products (ILRI and MINAGRI 2017). In fact, the LMP framed the key challenge in a rather technocratic way, as the "meat consumption gap" and described strategies to ensure Rwandans will increase their consumption of animal products. The participatory scenario planning process helped to open up this initial framing by taking into consideration a broad range of short-term and longer-term external drivers impacting the sector. This included socioeconomic, technological, political, and cultural short-term shocks, such as protests and uprisings in response to land grabbing and volatility of food prices, as well as longer-term developments (e.g., effects of laissez-faire capitalism and unsustainable land use), along with natural disturbances such as disease outbreaks and climatic shocks. It also helped to broaden the geographical scope, from predominantly focusing on local and national-level drivers, such as domestic market dynamics, to the consideration of East-African-level and global drivers impacting the system, such as global market forces and international political tensions:

This need has led to easier internal and external mobility/ movements with a general intolerance for inefficiencies and corruption which slow business development and limit regional competitiveness with other emerging regions (southern Africa, Southeast Asia) (Kiker et al. 2020:10). 
Table 3. Results.

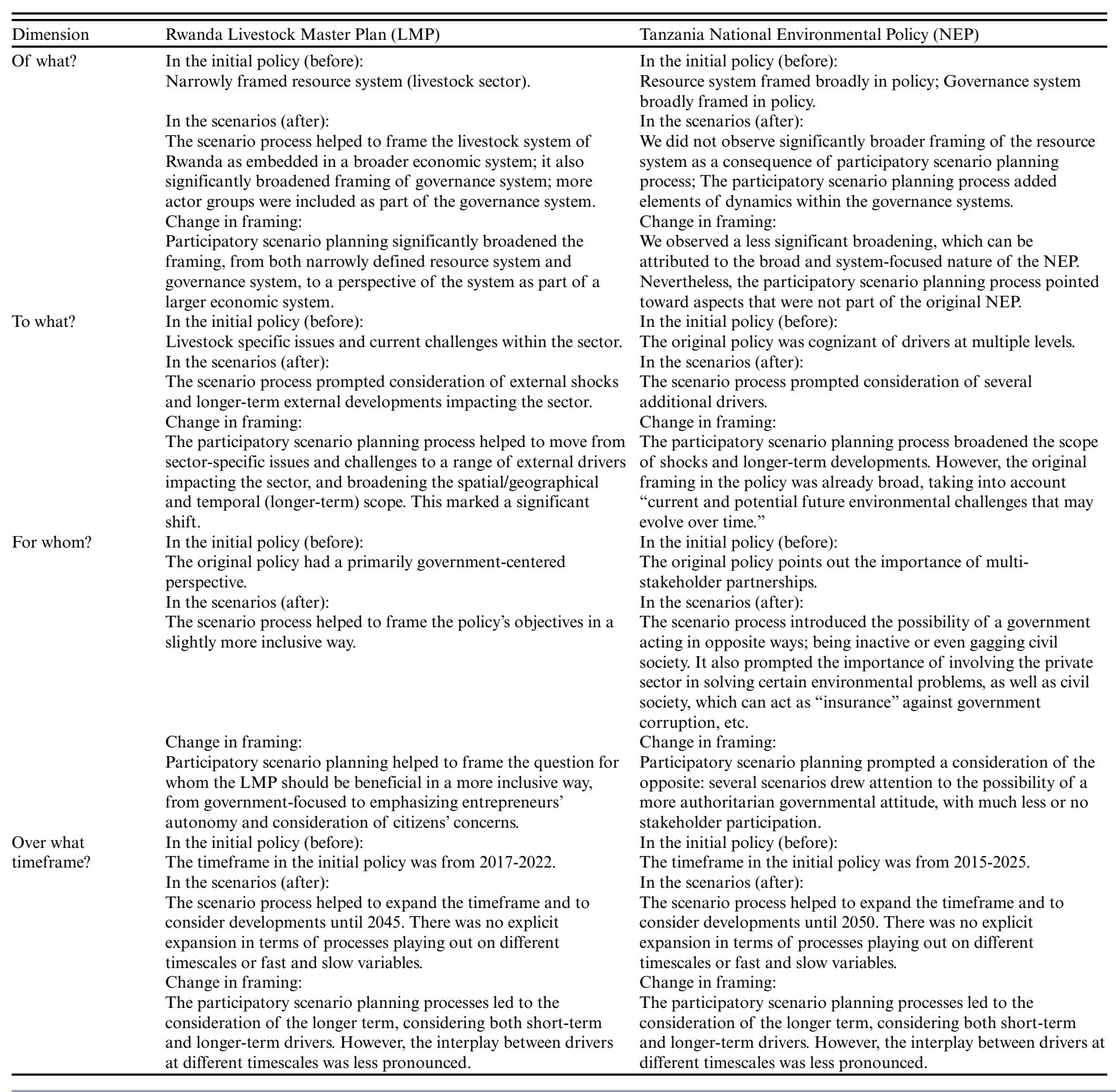

In the case of the Tanzanian NEP, we observed much less broadening in terms of framing of drivers. The participatory scenario planning process prompted the consideration of additional environmental, societal, economic, technological, and political developments that might occur (e.g., economic and political integration of East Africa, a growing middle class, widely available new technologies, or increased inequality). However, the initial policy stated that "current and potential future environmental challenges may evolve over time" (United Republic of Tanzania 2014:8), so its initial framing was already relatively broad. The original policy also recognized drivers at multiple levels, from the local to the global. The participatory scenario planning process helped to identify a number of new drivers to the conversation, especially in terms of political dimensions, such as increased awareness and political engagement of the general population, and increased influence of national and international lobby groups. Examples of this include:

In addition, these telecommunication technologies provided new advertising channels, accessible for small entrepreneurs as well. A positive effect of this has been increased awareness throughout the population. This 
proves to be an important instrument for combatting corruption. (Muchunguzi et al. 2015:41);

International NGOs and CSOs lobby the government to include training of people in rural activities (Muchunguzi et al. 2015:49).

\section{Dimension 3: for whom?}

Again, when analyzing the contribution of participatory scenario planning to the dimension 'for whom,' differences between the two cases were observed. In the case of the Rwandan LMP, the scenario process helped to move from an initial governmentfocused top-down framing toward one in which entrepreneurs were acknowledged as actors actively driving the sector, as exemplified by this quote:

The "Made in Rwanda" program, instigated by Rwanda's private sector, has been generally successful in creating a business-friendly atmosphere with improved public private partnerships and the promotion of value addition and locally made products (Kiker et al. 2020:9).

The initial LMP predominantly focused on pushing the Rwandan economy as a whole, with the logic being that this growth would contribute to eradicating poverty:

the livestock sector of Rwanda provides major opportunities to increase further its contribution to economic growth [...] while improving incomes to reduce poverty (ILRI and MINAGRI 2017:8).

As a result of the participatory scenario planning process, this shifted to a framing in which entrepreneurs within the sector are regarded as autonomous agents and citizens and their concerns are considered. However, some scenarios depict Rwanda as a country focused on GDP growth, and this aligns to a large degree to the objectives of the policy; entrepreneurs are regarded as the prime beneficiaries of the policy, while other actors are neglected to an extent. In addition, needs and concerns of Rwanda's general population were introduced into the conversation, instead of a one-sided focus on government's objectives (Kiker et al. 2020).

Interestingly, we observed more or less the opposite in the Tanzanian NEP case. The initial framing in the policy was one of inclusive governance, promoting multi-stakeholder partnerships to address the issues described in the policy:

The future agricultural and industrial processes are projected to be resource and energy efficient, low in water and carbon, low in emissions and pollution, low in loss of biodiversity and ecosystems, and socially inclusive (United Republic of Tanzania 2014:41);

Public-private partnership is essential for fund raising where by their inclusion in budgeting plan and decision making is critical for resource mobilization specifically in environmental management plan and strategies (United Republic of Tanzania 2014:74).

However, some of the scenarios pointed toward the possibility of the government acting in opposite ways; being inactive or becoming more authoritarian and even gagging civil society:

[...] the poor will have protests due to the high food prices as well as abusive human rights. To address this the government will employ use of excessive force as well as attempts to gag the civil society through banning some of the organizations and freezing their funding especially resources coming from abroad (Muchunguzi et al. 2015:36).

This encouraged promoting even more active involvement of nongovernmental actors as an "insurance" against authoritarian rule, i.e., "this pushes civil society, bolstered by international support, into a demand for radical change in governance" (Muchunguzi et al. 2015:32). It also prompted the importance of involving the private sector in solving certain environmental problems:

Only the private sector, which is amassing huge resources, will be able to effectively handle waste management both in the industries and home (Muchunguzi et al. 2015:36).

\section{Dimension 4: over what timeframe?}

Considering the contribution of participatory scenario planning to the dimension 'over what timeframe,' we observed less of a difference between the two cases we analyzed. In both cases, the scenario process helped to open up the time scope and take into consideration longer-term future developments and uncertainty. Both the Rwandan LMP and the Tanzanian NEP initially took into consideration a timeframe up to a decade (2017-2025 and 2015-2025, respectively). The scenario process contributed greatly to expanding the timeframe, prompting consideration of developments up till 2050, as exemplified by these quotes from the Rwanda and the Tanzania scenarios, respectively:

Now, twenty years later (in 2045), we may appear as a herd from the outside but the "old school" nationalist mindset actually persists and everyone - individuals, countries, have to fend for themselves. (Kiker et al. 2020:12);

Because of pro-active governance, different types of agricultural production have been made more climate resilient. Climatic shocks or unpredicted events have increased, but by 2040-50 most farmers are better prepared to cope with these (Muchunguzi et al. 2015:41).

The interplay between drivers at different timescales was, however, less pronounced.

\section{DISCUSSION AND CONCLUSIONS}

We investigated how participatory scenario planning contributes to system and problem framing. We did so by analyzing two scenario-guided policy formulation processes in East-Africa facilitated by the CCAFS Scenarios Project. On the whole, we concluded that participatory scenario planning contributes to all four dimensions we used to operationalize system and problem framing, i.e., 'of what?,' 'to what?,' 'for whom?,' and 'over what timeframe?'. We saw that participatory scenario planning primarily contributed to the dimension "to what?" in the two cases we analyzed, in terms of identifying additional drivers impacting the system, both in the short and longer term. As several of these additional drivers were perceived as threats to the system, or problems, we concluded participatory scenario planning contributed to problem framing. It helped to articulate interrelatedness of different drivers, or problems, related to the focus theme of the policy as well. We also observed that the extent to which it contributed to problem framing very much depended on the initial scope of the policy. In the case of the Tanzanian 
New Environmental Policy, which already had a very broad scope, we saw a more limited contribution in terms of system or problem reframing. It also contributed to the dimension 'of what?': in the case of the Rwanda LMP, a significant inclusion of context was observed, from solely focusing on the livestock sector, to considering the sector as embedded in the larger Rwandan, or even international economy. To a lesser degree, it also helped to articulate the role of societal and cultural aspects, such as actor perspectives and values. Importantly, participatory scenario planning led to greater consideration of connectedness of the focus system (the livestock system) with other systems such as natural ecosystems and society, thereby encouraging systems thinking. This corresponds with existing literature on scenarios and systems thinking. Chermack (2004a:27), for instance, argued that "scenarios and scenario planning can be viewed as systems" and can therefore articulate the characteristics and properties of systems very well, not least because system theory is an important and foundational theory for scenarios and scenario planning.

We also saw improvements regarding the dimension "for whom," albeit to a lesser degree. This can be attributed to the way the scenario process was organized in terms of participants that were invited. In both cases, the objective was to make the process as inclusive as possible, but due to dependence on governments' willingness and networks, both scenario processes were dominated by governmental actors. It is, however, important to note that the dimension "for whom?" not only refers to who is participating in the scenario process, but also applies to who are affected, have interests, and therefore should be involved in the broader governance processes.

We observed that the initial policy framing determined to a large extent how participatory scenario planning contributed to system and problem framing. In the Rwandan case, the scenario process helped to reframe the role of actors: actors in livestock value chains were attributed more agency as a result of the process. In the Tanzanian case, which was initially framed in a rather inclusive way, the possibility of a situation with a more autocratic government and less autonomy and influence of non-state actors was brought to the table. This can be considered a broadening of the framing, as the initial policy did not take this into account. So, in short, participatory scenario planning has the potential to contribute to the "for whom?" dimension, but this very much depends on the way the scenario process is organized. If organized in an inclusive way, through involvement of a diverse range of stakeholders, and by considering their interests and concerns and utilizing their knowledge and expertise, it can add to efficacy, legitimacy, and analytical rigor of governance.

With regard to the "for whom?" dimension, it is important to note that generally, within the CCAFS program, the objective is to involve governments, investors, non-governmental organizations (the so-called "next users") and, importantly, representatives of the final beneficiaries who ought to benefit from the impact generated by the science-policy engagement process (Dinesh et al. 2018). However, in practice this is not always possible due to a variety of reasons. As a result, the reframing resulting from a participatory scenario planning process does not always reflect a "good" reframing, i.e., an inclusive one.

Looking at the "over what timeframe?" dimension, we observed clear improvements when it comes to the time horizon considered in the policy process, as the scenario process helped to incorporate a long-term perspective. Moreover, by exploring multiple plausible scenarios, future uncertainty was acknowledged and taken into account explicitly in the policy process. However, SES processes taking place on different timescales and their interplay were less pronounced in the process.

We did not explicitly focus on a fifth dimension that might be useful: the spatial or geographical dimension. We argue that this dimension is partially addressed in the "of what?" dimension, which refers to the system of interest, and also entails its geographical location and scope. It would, however, be an interesting next step in this line of research to explicitly focus on the role of participatory scenario planning in the spatial dimension of system and problem framing.

In addition, we did not analyze the new policy documents because we decided to focus on the changes in framing brought about by the scenario planning process. In the Tanzanian case, the finalization of the policy was an internal process on which the government did not provide much transparency. In the Rwandan case, in which the policy formulation process was already in the final stages, the lessons from the participatory scenario process are to be utilized in ongoing and future policy processes and during implementation of the LMP. The timeframe and political nature of the processes complicated analysis of how the insights from the participatory scenario process ultimately translated into new policies. An important next step in this research will be to compare scenario-guided policy formulation processes that produced explicit policy outcomes with processes that did not lead to clear outcomes. This way, one could identify potential relationships between the extent to which the scenario process contributed to a change in system and problem framing, and how this is translated into actual policy.

Furthermore, we conclude that the extent to which participatory scenario planning contributes to system and problem framing of a policy very much depends on the initial framing of the policy. In the case of the Rwanda LMP, which had a narrow focus on the livestock sector, we observed a much bigger contribution to widening the scope of the framing than in the case of the Tanzania NEP, which initially already had a more holistic framing. We also saw that because of the initial policy perspective, the scenario process can be hijacked: this is what happened in the Rwandan LMP case when reviewing the LMP using the "Herd of Zebra" scenario. This particular scenario depicts a future world that corresponds to a large degree with the economic framing of the LMP. Interestingly, it reinforced some of the aspects of the LMP that could be considered problematic.

We argue that this is mainly due to the way the scenario process was set up, and the way the scenarios were developed. Participatory scenario planning processes could be designed in such a way that they more explicitly address questions about who is involved in or contributing to the decision-making process. Moreover, explicit questions about who is benefitting and who is affected negatively by the plan or policy under review can be asked. Furthermore, the scenario sets that were developed under the CCAFS Scenarios Project have a strong focus on contextual developments, thus emphasizing the "to what?" dimension. Explicit questions pertaining to the "for whom?" dimension and some aspects of the "over what timeframe?" dimension, i.e., fast 
and slow variables and their interplay, can be incorporated in a more articulated way in the development of the scenarios.

It is important to remark that effective science-policy engagement, and therefore participatory scenario planning, relies on a number of conditions, including shared understanding of goals, recognition of different stakeholder perspectives, protected spaces for joint knowledge production, and appropriate resources, both financial and methodological, to support these (Hegger et al. 2012, Dinesh et al. 2018). Even if these conditions are favorable, a number of additional challenges can occur, such as trade-offs between available time and resources and quality of the process and all kinds of organizational and institutional challenges. Furthermore, a shift from traditional state-centric governance to an approach that includes non-state actors, as is the case in both scenario processes we analyzed, makes science-policy engagement more complex because of a distribution of power among many societal actors (Meadowcroft 2007, Dinesh et al. 2018).

Moreover, we should take note that the effects of stakeholder participation are not undisputed, as opposed to Stirling's (1999) argument that stakeholder participation can enhance analytical rigor, several scholars have stressed that these effects are ambiguous, and that there are potential trade-offs between inclusiveness and analytical depth. For example, stakeholders who have been involved in decision making for a longer time often still have more influence than newer, less powerful stakeholders (Bulkeley and Mol 2003). In addition, it has been disputed that stakeholder participation contributes to higher legitimacy and inclusiveness of decision-making processes per se (Dietz and Stern 2008, Lange et al. 2013, Young et al. 2013, Newig et al. 2018). Another potential counterproductive effect is that involving multiple stakeholders increases the complexity of decision making, potentially leading to delays or deadlocks (Beierle and Cayford 2002). Moreover, the actual impact, in terms of more effective policies of participatory environmental governance processes, remains disputed (Newig and Fritsch 2009, Gerlak et al. 2013, Young et al. 2013). Although in general, participation is thought to have a positive effect on environmental governance outcomes, further research is needed to identify the mechanisms through which participation may lead to improved governance outcomes (Jager et al. 2020).

When looking at the broader foresight literature, which includes participatory scenario planning, we see that much has been written on its potential to elicit systems thinking (Barker and Smith 1995, Martin and Johnston 1999, Chermack 2004b, Zeithaml et al. 2006, Foran et al. 2013, Oteros-Rozas et al. 2015), to help connect stakeholder perspectives (Barker and Smith 1995, Cuhls 2003, Mietzner and Reger 2005), to help make explicit and question underlying cultural or individual assumptions of how the world works (Wack 1985b, Korte and Chermack 2007), and to enhance dialogue (Barker and Smith 1995, Martin 1995, Martin and Johnston 1999, Chermack 2004b, Mietzner and Reger 2005, Foran et al. 2013). However, work explicitly examining the contribution of foresight, or more specifically scenario planning, to system and problem framing has not been conducted to this point. Helfgott (2018) suggested that scenarios can be used to engage with the 'to what?' dimension of system resilience. We build on this work by Helfgott and others by demonstrating in practice exactly how participatory scenario planning can lead to broadened system and problem framing. As such, it also adds insight to scholarship on participatory problem framing, more specifically to what Dewulf et al. $(2009,2012)$ referred to as interactional issue framing. It also links to work on scenarios functioning as boundary objects enabling dialogue between different actor groups with different backgrounds and knowledge (e.g., Lang and Ramírez 2017, Hajer and Pelzer 2018). Furthermore, our findings provide an important contribution to the literature on participatory scenario planning applied in SES contexts, which sometimes touches upon system and problem framing, but has not explicitly examined the link with scenarios (e.g., Peterson et al. 2003, Kok et al. 2007, Vervoort et al. 2012b).

All in all, we observed that the scenario processes analyzed helped to make a range of aspects related to systems thinking be considered in policy formulation. It led to a consideration of connectedness between the focus system of the policy and other systems. Moreover, it led to broader problem framing and an increased sense of interrelatedness of problems. And additionally, it helped to bring different actor groups with different perspectives and societal values into the conversation. It greatly contributed in terms of broadening the time scope and the scope of external drivers considered. However, the contribution of participatory scenario planning to the "for whom?" dimension was not as clear. This can be partially explained by the roots of scenario planning. On the one hand, it stems from business foresight, in which performance of companies is central and in which the question "for whom?" is regarded primarily instrumental. On the other hand, it has firm roots in environmental assessments, in which economic and environmental science are dominant; models and scenarios used in these assessments typically do not incorporate aspects related to the "for whom?" dimension. However, our findings show the potential of participatory scenario planning to make the politics of policy and broader SES governance processes more explicit by more openly and explicitly addressing the "for whom?" dimension. Therefore, we recommend designing participatory scenario planning processes that make use of the insights from critical system theory, incorporating questions of who gets to decide how the system and problems are framed, what the objective of the policy is, who is supposed to benefit, whose knowledge and expertise is used, which world views are represented, and how concerns of marginalized groups are secured (Churchman 1970, Midgley 1992, Ulrich 1996, Midgley et al. 1998, Helfgott 2018).

\section{Responses to this article can be read online at: https://www.ecologyandsociety.org/issues/responses. php/12665}

\section{Data Availability:}

All data are made available. The workshop report of the scenarioguided policy review of the Rwanda Livestock Master Plan (Kiker et al. 2020) can be accessed here: https:/losf.io/gr2f6/. The workshop report of the Scenario-guided policy review of the 
Tanzania National Environmental Policy (Muchunguzi et al. 2015) can be accessed here: https:/losf.iolgs9nkl

\section{LITERATURE CITED}

Adger, W. N. 2000. Social and ecological resilience: are they related? Progress in Human Geography 24:347-364. https://doi. org/10.1191/030913200701540465

Adger, W. N., K. Brown, D. R. Nelson, F. Berkes, H. Eakin, C. Folke, K. Galvin, L. Gunderson, M. Goulden, K. O. Brien, J. Ruitenbeek, and E. L. Tompkins. 2011. Resilience implications of policy responses to climate change. Wiley Interdisciplinary Reviews: Climate Change 2:757-766. https://doi.org/10.1002/ wcc. 133

Ash, N., H. Blanco, C. Brown, K. Garcia, T. Henrichs, N. Lucas, C. Ruadsepp-Heane, R. D. Simpson, R. Scholes, T. P. Tomich, B. Vira, and M. Zurek. 2010. Ecosystems and human well-being: a manual for assessment practitioners. Island, Washington, D.C., USA. [online] URL: https://www.unep-wcmc.org/system/ dataset_file fields/files/000/000/109/original/EcosystemsHumanWellbeing. pdf?1398679213

Barker, D., and D. J. H. Smith. 1995. Technology foresight using roadmaps. Long Range Planning 28:21-28. https://doi. org/10.1016/0024-6301(95)98586-H

Beierle, T. C., and J. Cayford. 2002. Democracy in practice: public participation in environmental decisions. Resources for the Future, Washington, D.C., USA.

Berkes, F. 2003. Alternatives to conventional management: Lessons from small-scale fisheries. Environments 31:5-20. [online] URL: https://www.umanitoba.ca/institutes/natural_resources/ canadaresearchchair/Alternatives $\% 20$ to $\% 20$ Conventional $\%$ 20Management $\% 20-\% 20$ Lessons $\% 20$ from $\% 20$ Small-Scale $\% 20$ Fisheries. pdf

Berkes, F. 2017. Environmental governance for the anthropocene? Social-ecological systems, resilience, and collaborative learning. Sustainability 9(7):1232. https://doi.org/10.3390/su9071232

Berkes, F., and C. Folke, editors. 1998. Linking social and ecological systems: management practices and social mechanisms for building resilience. Cambridge University Press, New York, New York, USA.

Biggs, R., M. Schlüter, D. Biggs, E. L. Bohensky, S. BurnSilver, G. Cundill, V. Dakos, T. M. Daw, L. S. Evans, K. Kotschy, A. M. Leitch, C. Meek, A. Quinlan, C. Raudsepp-Hearne, M. D. Robards, M. L. Schoon, L. Schultz, and P. C. West. 2012. Toward principles for enhancing the resilience of ecosystem services. Annual Review of Environment and Resources 37:421-448. https://doi.org/10.1146/annurev-environ-051211-123836

Bohensky, E. L., B. Reyers, and A. S. Van Jaarsveld. 2006. Future ecosystem services in a Southern African river basin: a scenario planning approach to uncertainty. Conservation Biology 20:1051-1061. https://doi.org/10.1111/j.1523-1739.2006.00475.x

Brugnach, M., A. Dewulf, H. J. Henriksen, and P. van der Keur. 2011. More is not always better: coping with ambiguity in natural resources management. Journal of Environmental Management 92:78-84. https://doi.org/10.1016/j.jenvman.2010.08.029
Brugnach, M., A. Dewulf, C. Pahl-wostl, and T. Taillieu. 2008. Toward a relational concept of uncertainty: about knowing too little, Knowing too differently, and accepting not to know. Ecology and Society 13(2):30. https://doi.org/10.5751/ES-02616-130230

Brugnach, M., and H. Ingram. 2012. Ambiguity: the challenge of knowing and deciding together. Environmental Science and Policy 15:60-71. https://doi.org/10.1016/j.envsci.2011.10.005

Bulkeley, H., and A. P. J. Mol. 2003. Participation and environmental governance: consensus, ambivalence and debate. Environmental Values 12:143-154. https://doi.org/10.3197/0963$\underline{27103129341261}$

Carpenter, S., B. Walker, J. M. Anderies, and N. Abel. 2001. From metaphor to measurement: resilience of what to what? Ecosystems 4:765-781. https://doi.org/10.1007/s10021-001-0045-9

Cash, D. W. W. N. Adger, F. Berkes, P. Garden, L. Lebel, P. Olsson, L. Pritchard, and O. Young. 2006. Scale and cross-scale dynamics: governance and information in a multilevel world. Ecology and Society 11(2):8. https://doi.org/10.5751/ES-01759-110208

Chaudhury, M., J. Vervoort, P. Kristjanson, P. Ericksen, and A. Ainslie. 2013. Participatory scenarios as a tool to link science and policy on food security under climate change in East Africa. Regional Environmental Change 13:389-398. https://doi. org/10.1007/s10113-012-0350-1

Chermack, T. J. 2004a. The role of system theory in scenario planning. Journal of Futures Studies 8:15-30. [online] URL: https://jfsdigital.org/articles-and-essays/2004-2/vol-8-no-4-may-2004/ articles/the-role-of-system-theory-in-scenario-planning/

Chermack, T. J. 2004b. Improving decision-making with scenario planning. Futures 36:295-309. https://doi.org/10.1016/S0016-3287 (03)00156-3

Churchman, C. W. 1970. Operations research as a profession. Management Science 17. https://doi.org/10.1287/mnsc.17.2.B37

Cretney, R. 2014. Resilience for whom? Emerging critical geographies of socio-ecological resilience. Geography Compass 8:627-640. https://doi.org/10.1111/gec3.12154

Cuhls, K. 2003. From forecasting to foresight processes - new participative foresight activities in Germany. Journal of Forecasting 22:93-111. https://doi.org/10.1002/for.848

Cumming, G. S., D. H. M. Cumming, and C. L. Redman. 2006. Scale mismatches in social-ecological systems: causes, consequences, and solutions. Ecology and Society 11(1):14. https://doi.org/10.5751/ES-01569-110114

Dewulf, A., and R. Bouwen. 2012. Issue framing in conversations for change: discursive interaction strategies for "doing differences.” Journal of Applied Behavioral Science 48:168-193. https://doi.org/10.1177/0021886312438858

Dewulf, A., M. Craps, R. Bouwen, T. Taillieu, and C. Pahl-Wostl. 2005. Integrated management of natural resources: dealing with ambiguous issues, multiple actors and diverging frames. Water Science and Technology 52:115-124. https://doi.org/10.2166/ wst.2005.0159 
Dewulf, A., M. Craps, and G. Dercon. 2004. How issues get framed and reframed when different communities meet: a multilevel analysis of a collaborative soil conservation initiative in the Ecuadorian Andes. Journal of Community and Applied Social Psychology 192:177-192. https://doi.org/10.1002/casp.772

Dewulf, A., B. Gray, L. Putnam, R. Lewicki, N. Aarts, R. Bouwen, and C. van Woerkum. 2009. Disentangling approaches to framing in conflict and negotiation research: a meta-paradigmatic perspective. Human Relations 62:155-193. https://doi. org/10.1177/0018726708100356

Dietz, T., and P. C. Stern. 2008. Public participation in environmental assessment and decision making. National Academies Press, Washington, D.C., USA. https://doi. org/10.17226/12434

Dinesh, D., R. B. Zougmore, J. Vervoort, E. Totin, P. K. Thornton, D. Solomo, P. B. Shirsath, V. O. Pede, I. Lopez Noriega, P Läderach, J. Körner, D. Hegger, E. H. Girvetz, A. E. Friis, P. P. J. Driessen, and B. M. Campbell. 2018. Facilitating change for climate-smart agriculture through science-policy engagement. Sustainability 10:1-21. https://doi.org/10.3390/su10082616

Dryzek, J. S. 2000. Deliberative democracy and beyond: liberals, critics, and contestations. Oxford University Press, Oxford, UK.

Fahey, L., and R. M. Randall. 1998. Learning from the future competitive foresight scenarios. John Wiley and Sons, New York, New York, USA.

Folke, C. 2006. Resilience: the emergence of a perspective for social-ecological systems analyses. Global Environmental Change 16:253-267. https://doi.org/10.1016/j.gloenvcha.2006.04.002

Folke, C. 2007. Social-ecological systems and adaptive governance of the commons. Ecological Research 22:14-15. https://doi.org/10.1007/s11284-006-0074-0

Folke, C., S. R. Carpenter, B. Walker, M. Scheffer, T. Chapin, and J. Rockström. 2010. Resilience thinking: integrating resilience, adaptability and transformability. Ecology and Society 15(4):20. https://doi.org/10.5751/ES-03610-150420

Foran, T., J. Ward, E. J. Kemp-Benedict, and A. Smajgl. 2013. Developing detailed foresight narratives: a participatory technique from the Mekong region. Ecology and Society 18(4):6. https://doi.org/10.5751/ES-05796-180406

Garb, Y., S. Pulver, and S. D. VanDeveer. 2008. Scenarios in society, society in scenarios: toward a social scientific analysis of storyline-driven environmental modeling. Environmental Research Letters 3:1-8. https://doi.org/10.1088/1748-9326/3/4/045015

Gerlak, A. K., T. Heikkila, and M. Lubell. 2013. The promise and performance of collaborative governance. Pages 413-434 in S. Kamieniecki and M. E. Kraft, editors. Oxford Handbook of U.S. Environmental Policy. Oxford University Press, Oxford, UK. https://doi.org/10.1093/oxfordhb/9780199744671.013.0019

Gibbons, M. 1999. Science's new social contract with society. Nature 402:C81-C84. https://doi.org/10.1038/35011576

Giordano, R., M. Brugnach, and I. Pluchinotta. 2017. Ambiguity in problem framing as a barrier to collective actions: some hints from groundwater protection policy in the Apulia Region. Group Decision and Negotiation 26:911-932. https://doi.org/10.1007/ s10726-016-9519-1

Glucker, A. N., P. P. J. Driessen, A. Kolhoff, and H. A. C. Runhaar. 2013. Public participation in environmental impact assessment: why, who and how? Environmental Impact Assessment Review 43:104-111. https://doi.org/10.1016/j.eiar.2013.06.003

Hajer, M. A., and P. Pelzer. 2018. 2050 - an energetic odyssey: understanding 'techniques of futuring' in the transition towards renewable energy. Energy Research and Social Science 44:222-231. https://doi.org/10.1016/j.erss.2018.01.013

Hegger, D., M. Lamers, A. Van Zeijl-Rozema, and C. Dieperink. 2012. Conceptualising joint knowledge production in regional climate change adaptation project: success conditions and levers for action. Environmental Science and Policy 18:52-65. https:// doi.org/10.1016/j.envsci.2012.01.002

Helfgott, A. 2018. Operationalising systemic resilience. European Journal of Operational Research 268:852-864. https://doi. org/10.1016/j.ejor.2017.11.056

Herrera, H. 2017. Resilience for whom? The problem structuring process of the resilience analysis. Sustainability 9:1-17. https:// doi.org/10.3390/su9071196

International Livestock Research Institute (ILRI), and Rwanda Ministry of Agriculture and Animal Resources (MINAGRI). 2017. Rwanda livestock master plan. FAO, Rome, Italy. [online] URL: http://extwprlegs1.fao.org/docs/pdf/rwa172923.pdf

Jager, N. W., J. Newig, E. Challies, and E. Kochskämper. 2020. Pathways to implementation: evidence on how participation in environmental governance impacts on environmental outcomes. Journal of Public Administration Research and Theory 30:383399. https://doi.org/10.1093/jopart/muz034

Kiker, G., L. Rutting, and P. K. Thornton. 2020. Future livestock systems: scenario-guided review of the Rwanda Livestock Master Plan [workshop report]. USAID, Gainesville, Florida, USA.

Kok, K., R. O. Biggs, and M. Zurek. 2007. Methods for developing multiscale participatory scenarios: insights from Southern Africa and Europe. Ecology and Society 12(1):8. [online] URL: http://www.ecologyandsociety.org/vol12/iss1/art8/

Kok, K., M. Patel, D. S. Rothman, and G. Quaranta. 2006. Multiscale narratives from an IA perspective: part II. Participatory local scenario development. Futures 38:285-311. https://doi. org/10.1016/j.futures.2005.07.006

Korte, R. F., and T. J. Chermack. 2007. Changing organizational culture with scenario planning. Futures 39:645-656. https://doi. org/10.1016/j.futures.2006.11.001

Lang, T., and R. Ramírez. 2017. Building new social capital with scenario planning. Technological Forecasting and Social Change 124:51-65. https://doi.org/10.1016/j.techfore.2017.06.011

Lange, P., P. P. J. Driessen, A. Sauer, B. Bornemann, and P. Burger. 2013. Governing towards sustainability — conceptualizing modes of governance. Journal of Environmental Policy and Planning 15:403-425. https://doi.org/10.1080/1523908X.2013.769414 
Lebel, L., J. M. Anderies, B. Campbell, C. Folke, S. HatfieldDodds, T. P. Hughes, and J. Wilson. 2006. Governance and the capacity to manage resilience in regional social-ecological systems. Ecology and Society 11(1):19. https://doi.org/10.5751/ ES-01606-110119

Lord, S., A. Helfgott, and J. M. Vervoort. 2016. Choosing diverse sets of plausible scenarios in multidimensional exploratory futures techniques. Futures 77:11-27. https://doi.org/10.1016/j. futures.2015.12.003

Maier, H. R., J. H. A. Guillaume, H. van Delden, G. A. Riddell, M. Haasnoot, and J. H. Kwakkel. 2016. An uncertain future, deep uncertainty, scenarios, robustness and adaptation: how do they fit together? Environmental Modelling and Software 81:154-164. https://doi.org/10.1016/j.envsoft.2016.03.014

Martin, B. R. 1995. Foresight in science and technology. Technology Analysis and Strategic Management 7:139-168. https://doi.org/10.1080/09537329508524202

Martin, B. R., and R. Johnston. 1999. Technology foresight for wiring up the national innovation system: experiences in Britain, Australia, and New Zealand. Technological Forecasting and Social Change 60:37-54. https://doi.org/10.1016/S0040-1625(98) $\underline{00022-5}$

Meadowcroft, J. 2007. Who is in charge here? Governance for sustainable development in a complex world*. Journal of Environmental Policy and Planning 9:299-314. https://doi. org/10.1080/15239080701631544

Meerow, S., and J. P. Newell. 2019. Urban resilience for whom, what, when, where, and why? Urban Geography 40:309-329. https://doi.org/10.1080/02723638.2016.1206395

Midgley, G. 1992. The sacred and profane in critical systems thinking. Systems Practice 5:5-16. https://doi.org/10.1007/ $\underline{\mathrm{BF} 01060044}$

Midgley, G., I. Munlo, and M. Brown. 1998. The theory and practice of boundary critique: developing housing services for older people. Journal of the Operational Research Society 49:467-478. https://doi.org/10.1057/palgrave.jors.2600531

Mietzner, D., and G. Reger. 2005. Advantages and disadvantages of scenario approaches for strategic foresight. International Journal of Technology Intelligence and Planning 1:220-239. https://doi.org/10.1504/IJTIP.2005.006516

Millenium Ecosystem Assessment (MEA). 2005. Ecosystems and human well-being: synthesis. Island, Washington, D.C., USA. [online] URL: https://www.millenniumassessment.org/documents/ document.356.aspx.pdf

Mostert, E., C. Pahl-wostl, Y. Rees, B. Searle, D. Tàbara, and J. Tippett. 2007. Social learning in European river-basin management: barriers and fostering mechanisms from 10 river basins. Ecology and Society 12(1):19. [online] URL:http://www. ecologyandsociety.org/vol12/iss1/art19/

Muchunguzi, P., E. Ampaire, M. Tumuhereze, C. Mongwera, J. M. Vervoort, and L. Rutting. 2015. Scenario-guided policy development in Tanzania in the context of climate change: a review of the National Environmental Policy. CCAFS, Wageningen, The Netherlands.
Newig, J., E. Challies, N. W. Jager, E. Kochskaemper, and A. Adzersen. 2018. The environmental performance of participatory and collaborative governance: a framework of causal mechanisms. Policy Studies Journal 46:269-297. https://doi. org/10.1111/psj.12209

Newig, J., and O. Fritsch. 2009. Environmental governance: participatory, multi-Level - and effective? Environmental Policy and Governance 19:197-214. https://doi.org/10.1002/eet.509

O'Faircheallaigh, C. 2010. Public participation and environmental impact assessment: purposes, implications, and lessons for public policy making. Environmental Impact Assessment Review 30:19-27. https://doi.org/10.1016/j.eiar.2009.05.001

Ostrom, E. 2009. A general framework for analyzing sustainability of social-ecological systems. Science 325:419-423. https://doi.org/10.1126/science.1172133

Ostrom, E. 2011. Background on the institutional analysis and development framework. Policy Studies Journal 39:7-27. https:// doi.org/10.1111/j.1541-0072.2010.00394.X

Oteros-Rozas, E., B. Martín-López, T. Daw, E. L. Bohensky, J. Butler, R. Hill, J. Martin-Ortega, A. Quinlan, F. Ravera, I. RuizMallén, M. Thyresson, J. Mistry, I. Palomo, G. D. Peterson, T. Plieninger, K. A. Waylen, D. M. Beach, I. C. Bohnet, M. Hamann, J. Hanspach, K. Hubacek, S. Lavorel, and S. P. Vilardy. 2015. Participatory scenario planning in place-based social-ecological research: insights and experiences from 23 case studies. Ecology and Society 20(4):32. http://dx.doi.org/10.5751/ES-07985-200432

Palazzo, A., J. M. Vervoort, D. Mason-D’Croz, L. Rutting, P. Havlik, S. Islam, J. Bayala, H. Valin, H. A. Kadi Kadi, P. Thornton, and R. Zougmore. 2017. Linking regional stakeholder scenarios and shared socioeconomic pathways: quantified West African food and climate futures in a global context. Global Environmental Change 45:227-242. https://doi.org/10.1016/j. gloenvcha.2016.12.002

Patel, M., K. Kok, and D. S. Rothman. 2007. Participatory scenario construction in land use analysis: an insight into the experiences created by stakeholder involvement in the Northern Mediterranean. Land Use Policy 24:546-561. https://doi. org/10.1016/j.landusepol.2006.02.005

Peterson, G. D., G. S. Cumming, and S. R. Carpenter. 2003. Scenario planning: a tool for conservation in an uncertain world. Conservation Biology 17:358-366. https://doi.org/10.1046/ j.1523-1739.2003.01491.x

Pulver, S., and S. D. VanDeveer. 2009. "Thinking about tomorrows": scenarios, global environmental politics, and social science scholarship. Global Environmental Politics 9:1-13. https:// doi.org/10.1162/glep.2009.9.2.1

Ramírez, R., and C. Selin. 2014. Plausibility and probability in scenario planning. Foresight 16:54-74. https://doi.org/10.1108/ FS-08-2012-0061

Schoemaker, P. J. H. 1993. Multiple scenario development: its conceptual and behavioral foundation. Strategic Management Journal14:193-213. https://doi.org/10.1002/smj.4250140304 
Schoemaker, P. J. H., G. S. Day, and S. A. Snyder. 2013. Integrating organizational networks, weak signals, strategic radars and scenario planning. Technological Forecasting and Social Change 80:815-824. https://doi.org/10.1016/j.techfore.2012.10.020

Schoemaker, P. J. H., and P. E. Tetlock. 2012. Taboo scenarios: how to think about the unthinkable. California Management Review 54:5-25. https://doi.org/10.1525/cmr.2012.54.2.5

Schwartz, P. 1991. The art of the long view: planning for the future in an uncertain world. Doubleday, New York, New York, USA.

Shepherd, A., and C. Bowler. 1997. Beyond the requirements: improving public participation in EIA. Journal of Environmental Planning and Management 40:725-738. https://doi. org/10.1080/09640569711877

Smith, A., and A. Stirling. 2010. The politics of social-ecological resilience and sustainable socio-technical transitions. Ecology and Society 15(1):11. https://doi.org/10.5751/ES-03218-150111

Stirling, A. 1999. The appraisal of sustainability: some problems and possible responses. International Journal of Justice and Sustainability 4:111-135. https://doi.org/10.1080/13549839908725588

Tendall, D. M., J. Joerin, B. Kopainsky, P. Edwards, A. Shreck, Q. B. Le, P. Kruetli, M. Grant, and J. Six. 2015. Food system resilience: defining the concept. Global Food Security 6:17-23. https://doi.org/10.1016/j.gfs.2015.08.001

Turnpenny, J. R., A. J. Jordan, D. Benson, and T. Rayner. 2015. The tools of policy formulation: an introduction. Pages 3-29 in A. J. Jordan and J. R. Turnpenny, editors. The tools of policy formulation: actors, capacities, venues and effects. Edward Elgar, Cheltenham, UK. https://doi.org/10.4337/9781783477043.00011

Ulrich, W. 1994. Can we secure future-responsive management through systems thinking and design? Interfaces 24:26-37.

Ulrich, W. 1996. A primer to critical systems heuristics for action researchers. Centre for Systems Studies, University of Hull, Hull, UK. [online] URL: https://wulrich.com/downloads/ulrich 1996a. pdf

United Republic of Tanzania, Vice President' Office. 2014. First draft revised national environmental policy. United Republic of Tanzania, Dodoma, Tanzania.

van der Heijden, K. 1996. Scenarios: the art of strategic conversation. John Wiley and Sons, Chichester, UK.

van Notten, P. W. F., J. Rotmans, M. B. A. van Asselt, and D. S. Rothman. 2003. An updated scenario typology. Futures 35:423-443. https://doi.org/10.1016/S0016-3287(02)00090-3

Vermeulen, S., and B. Campbell. 2015. Ten principles for effective AR4D programs change adaptation and mitigation. CGIAR Research Program on Climate Change, Agriculture and Food Security (CCAFS), Copenhagen, Denmark. [online] URL: https://cgspace.cgiar.org/rest/bitstreams/58878/retrieve

Vermeulen, S. J., A. J. Challinor, P. K. Thornton, B. M. Campbell, N. Eriyagama, J. M. Vervoort, J. Kinyangi, A. Jarvis, P. Läderach, J. Ramirez-Villegas, K. J. Nicklin, E. Hawkins, and D. R. Smith. 2013. Addressing uncertainty in adaptation planning for agriculture. Proceedings of the National Academy of Sciences 110:8357-8362. https://doi.org/10.1073/pnas.1219441110

Vervoort, J. M., K. Kok, P.-J. Beers, R. Van Lammeren, and R. Janssen. 2012b. Combining analytic and experiential communication in participatory scenario development. Landscape and Urban Planning 107:203-213. https://doi. org/10.1016/j.landurbplan.2012.06.011

Vervoort, J. M., A. Palazzo, D. Mason-D’Croz, P. J. Ericksen, P. K. Thornton, P. Kristjanson, W. Förch, M. Herrero, P. Havlik, C. Jost, and H. Rowlands. 2013. The future of food security, environments and livelihoods in Eastern Africa: four socioeconomic scenarios. CCAFS Working Paper no. 63. CGIAR Research Program on Climate Change, Agriculture and Food Security (CCAFS), Copenhagen, Denmark. [online] URL: https://ccafs.cgiar.org/resources/publications/future-food-securityenvironments-and-livelihoods-eastern-africa-four

Vervoort, J. M., L. Rutting, K. Kok, F. L. P. Hermans, T. Veldkamp, A. K. Bregt, and R. van Lammeren. 2012a. Exploring dimensions, scales, and cross-scale dynamics from the perspectives of change agents in social-ecological systems. Ecology and Society 17(4):24. http://dx.doi.org/10.5751/ ES-05098-170424

Vervoort, J. M., P. K. Thornton, P. Kristjanson, W. Förch, P. J. Ericksen, K. Kok, J. S. I. Ingram, M. Herrero, A. Palazzo, A. E. S. Helfgott, A. Wilkinson, P. Havlík, D. Mason-D'Croz, and C. Jost. 2014. Challenges to scenario-guided adaptive action on food security under climate change. Global Environmental Change 28:383-394. https://doi.org/10.1016/j.gloenvcha.2014.03.001

Wack, P. 1985a. Scenarios: uncharted waters ahead. Harvard Business Review 63:73-89. [online] URL: https://hbr.org/1985/09/ scenarios-uncharted-waters-ahead

Wack, P. 1985b. Scenarios: shooting the rapids. Harvard Business Review 63:139-151. [online] URL: https://hbr.org/1985/11/ scenarios-shooting-the-rapids

Walker, B. H., S. R. Carpenter, J. Rockstrom, A.-S. Cr pin, and G. D. Peterson. 2012. Drivers, "Slow" variables, "fast" variables, shocks, and resilience. Ecology and Society 17(3):30. http://dx.doi.org/10.5751/ES-05063-170330

Whyte, W. F. 1991. Participatory action research. Sage, Thousand Oaks, California, USA.

Wiebe, K., M. Zurek, S. Lord, N. Brzezina, G. Gabrielyan, J. Libertini, A. Loch, R. Thapa-Parajuli, J. Vervoort, and H. Westhoek. 2018. Scenario development and foresight analysis: exploring options to inform choices. Annual Reviews of Environment and Resources 43:545-570. https://doi.org/10.1146/ annurev-environ-102017-030109

Wilkinson, A., and E. Eidinow. 2008. Evolving practices in environmental scenarios: a new scenario typology. Environmental Research Letters 3:1-11. https://doi.org/10.1088/1748-9326/3/4/045017

Young, J. C., A. Jordan, K. R. Searle, A. Butler, D. S. Chapman, P. Simmons, and A. D. Watt. 2013. Does stakeholder involvement really benefit biodiversity conservation? Biological Conservation 158:359-370. https://doi.org/10.1016/j.biocon.2012.08.018 
Ecology and Society 26(4): 20

Zeithaml, V. A., R. N. Bolton, J. Deighton, T. L. Keiningham, K. N. Lemon, and J. A. Petersen. 2006. Forward-looking focus: can firms have adaptive foresight? Journal of Service Research 9:168-183. 


\section{Appendix 1. CCAFS East Africa scenarios}

The CCAFS East Africa scenarios were developed during four workshops organized in 2010 and 2011 - 120 stakeholders from Kenya, Tanzania, Ethiopia, Uganda, Rwanda and Burundi, as well as regional and global actors came together to develop exploratory scenarios with the aim to guide decision-making processes in the region related to food security, environments and livelihoods. These included farmers' organizations, policy advisors, regional governance bodies such as the East African Community, research organizations, regional NGOs, private sector organizations, regional media and civil society organizations (Vervoort et al. 2013).

The scenarios were developed for the period 2010-2030. Two drivers were considered highly relevant for future food security, environments and livelihoods in Eastern Africa, but with high levels of uncertainty attached to them:

- Regional integration: Will the countries of Eastern Africa integrate politically and economically, or will a fragmented status quo be maintained?

- Mode of governance: Will governance - the rules, regulations, institutions and processes affecting the behaviour of individuals and groups - be characterized by a reactive or proactive stance of governments, the private sector and civil society?

These two drivers were used to structure four scenarios. These are displayed in figure 1, with cartoon representations by artist Mauvine Were. Here, we provide the summarized scenario narratives, which were named after animals inhabiting the East-African savannahs.

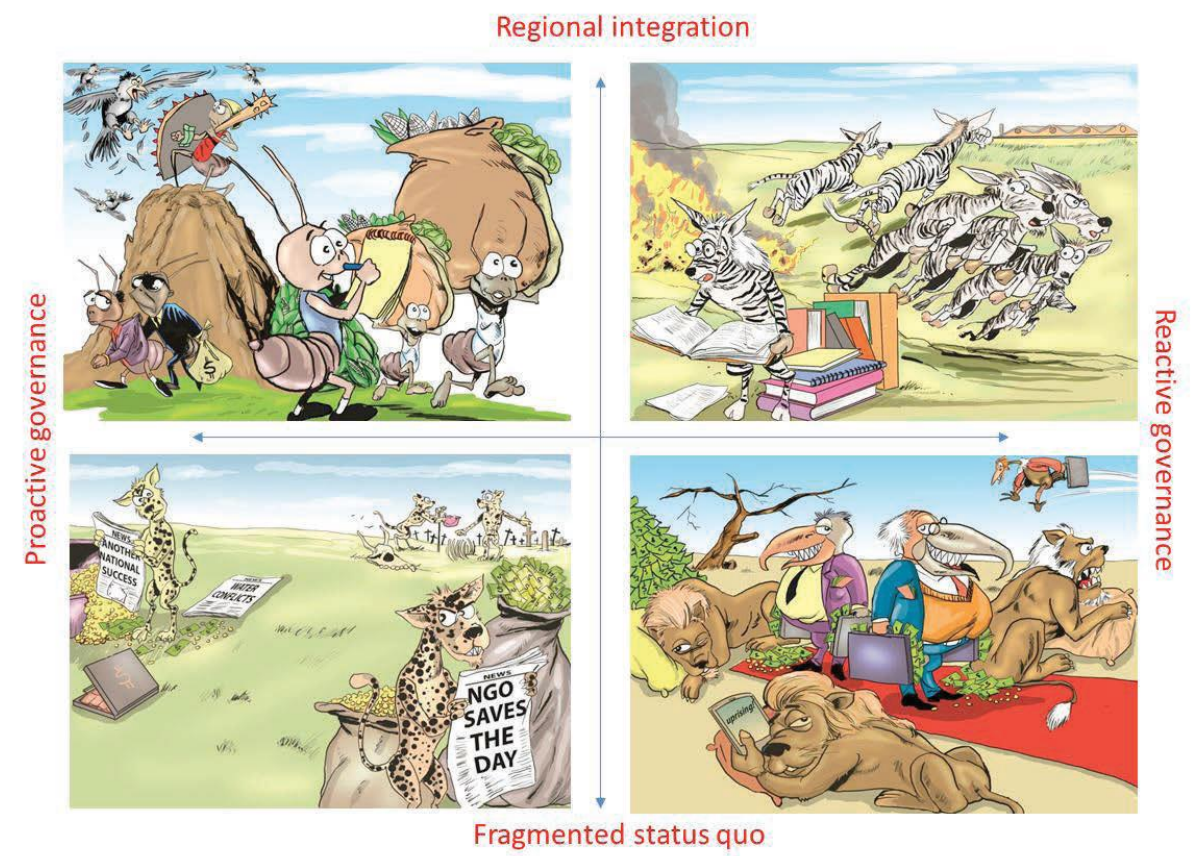


Figure 1. Cartoon representations of the CCAFS East Africa scenarios (from Vervoort et al. 2013)

\section{Scenario 1: Industrious Ants}

This scenario is characterized by the slow but strong economic and political development of East Africa and proactive government actions to improve regional food security; however, there are costly battles with corruption and security is fragile as the region has to deal with new international tensions resulting from its assertion in the global political and economic arena. The region's focus away from export-only commercial crops causes some challenges to compete on the global market - and the region's dedication on regional self-reliance proves to be challenging when a great drought hits in the early 2020 s - though by that time many state and non-state support structures are in place to help mitigate the worst impacts. Governments and non-state actors struggle to mitigate the environmental impacts of growing food and energy production.

\section{Scenario 2: Herd of Zebra}

In this scenario, governments and non-state actors are dedicated to a push for development - but mainly through industry, services, tourism and agriculture for export. In terms of food security, environments and livelihoods there is limited action. Natural lands decline. East African economies are booming but the region suffers the consequences of a double vulnerability - to global markets and environmental change. Only when food insecurity becomes extreme after food import prices skyrocket at the time of a great drought in the early 2020s are actions taken to govern water resources and invest in climatesmart food production for regional consumption.

\section{Scenario 3: Lone Leopards}

In this scenario, regional integration exists only on paper. In reality, governments and non-state actors are securing their own interests. In terms of food security, environments and livelihoods, the region initially seems to be heading toward catastrophe. However, after some years many regional state/nonstate partnerships become very pro-active and, unburdened by tight regional regulations and supported by international relations, are able to achieve some great successes. Unfortunately, this is a hit-and-miss world because of the lack of coordinated efforts and key problems are ignored. Governments' inability to overcome regional disputes and collaborate becomes untenable when a major drought hits in 2020 . This phenomenon pushes civil society, bolstered by international support, to demand radical change in governments. The change sticks in many cases, and for the better.

\section{Scenario 4: Sleeping Lions}

This scenario is all about wasted potential and win-lose games. Governments are reactive and selfinterested - allowing foreign interests free reign in the region. This has devastating consequences for food security, livelihoods and environments in the region. Conflicts, protests and uprisings are common, 
and every time there is the promise of reform, it rarely materializes into any real change. Only at the very end of the period do the first signs of better governance emerge - but the future is still very uncertain. With no coordinated efforts to deal with climate impacts, a great drought in the early 2020 s causes massive losses among the region's poor - and only communities' adaptive capacity and resilience, born out of decades of forced self-reliance, informal economies and the ability to share key knowledge can help mitigate some of the worst effects of this disaster. 